\section{Factors Associated with Self-Reported HIV Testing Among Persons 18 Years and Over in the United States - Findings from the 2012 Behavioral Risk Factor Surveillance System (BRFSS)}

\section{Gemechu B Gerbi ${ }^{1,2 *}$, Elaine Archie-Booker ${ }^{1,2}$, Mechelle D} Claridy $^{2}$ and Stephanie Miles-Richardson ${ }^{1,2}$

${ }^{1}$ Department of Community Health and Preventive Medicine, Morehouse School of Medicine, Atlanta, USA

${ }^{2}$ Master of Public Health Program, Morehouse School of Medicine, Atlanta, USA

\begin{abstract}
Background

The Centers for Disease Control and Prevention (CDC) estimates that 14 percent of persons infected with HIV in the United States (US) are unaware of their infection and many of the estimated 50,000 new HIV infections each year are transmitted by people who do not know that they are HIV-positive. HIV testing is an important component of HIV prevention. This study examined predictors of self-reported HIV testing among persons 18 years and over in the US.

\section{Methods}

Data from the 2012 BRFSS were utilized. We used univariate analysis to calculate relative frequencies for gender, race or ethnicity, age, education, income, marital status, region of residence, and having engaged in HIVIAIDS risky behaviors to characterize the overall sample. We conducted bivariate analysis for an initial assessment of factors independently associated with HIV testing. Multivariable logistic regression models were used to obtain the Adjusted Odds Ratios (AORs) and 95\% Confidence Intervals (95\% $\mathrm{Cls}$ ) for factors associated with getting tested for HIV. Analyses were conducted using SAS version 9.2.
\end{abstract}

*Corresponding author: Gemechu B Gerbi, Department of Community Health and Preventive Medicine, Morehouse School of Medicine, West view Dr. SW, Atlanta, GA, USA, Tel: +1 4047521500; E-mail: ggerbi@msm.edu

Citation: Gerbi GB, Archie-Booker E, Claridy MD, Miles-Richardson S (2016) Factors Associated with Self-Reported HIV Testing Among Persons 18 Years and Over in the United States - Findings from the 2012 Behavioral Risk Factor Surveillance System (BRFSS). J Infect Non Infect Dis 2: 013.

Received: December 01, 2015; Accepted: March 04, 2016; Published: March 18, 2016

\begin{abstract}
Results
Of the 439,327 respondents, $30 \%$ had been tested for HIV. Of those who had been tested for HIV, $59 \%$ were female; $41 \%$ were two or more races and $47 \%$ were between $18-44$ years of age. The majority $(39 \%)$ of the respondents were college graduates. Over one-third $(31 \%)$ of the participants who had been tested had annual household incomes which were less than $\$ 25,000$. Half $(50 \%)$ were married and $24 \%$ of the respondents were from the Western region of the US. Five percent of the respondents reported that they had engaged in HIVIAIDS risky behaviors. Factors associated with lower odds of getting tested included being Asian ( $A O R=0.56 ; 95 \% \mathrm{Cl}=0.41$, 0.78); Native Hawaiian or Other Pacific Islander (AOR $=0.42 ; 95 \%$ $\mathrm{Cl}=0.18,0.90$ ); and having an income between $\$ 25,000$ to $\$ 49,000$ (AOR=0.82; $95 \% \mathrm{Cl}=0.78-0.87$ ); $\$ 50,000$ to $\$ 74,999$ (AOR=0.86; $95 \% \mathrm{Cl}=0.79-0.93)$; or $\$ 75,000$ or more $(\mathrm{AOR}=0.87 ; 95 \% \mathrm{Cl}=0.81$ 0.94). Also, respondents from the Midwest (AOR $=0.78 ; 95 \%$ $\mathrm{Cl}=0.73,0.83)$ and the West $(\mathrm{AOR}=0.88 ; 95 \% \mathrm{Cl}=0.83,0.93)$ were less likely to get tested for HIV. Our adjusted analyses also showed that being non-Hispanic Black or African American, Hispanic or Latino, identifying as having two or more races, and being American Indian or Alaska Native increased the likelihood of getting tested for HIV. Having engaged in HIVIAIDS risky behaviors had significantly higher odds of being tested for HIV (AOR=2.45; $95 \% \mathrm{Cl}=2.19,2.74)$.

Conclusion
\end{abstract}

Our findings suggest that the HIVIAIDS prevention education and training programs in the US that have focused on traditionally classified high-risk populations have been effective. Findings from this study uncover an interesting paradox, which suggests that populations with higher incomes have been overlooked in efforts to combat HIVIAIDS. Our results suggest that these populations are at greatest risk of not knowing their HIV status and are therefore most likely to unknowingly contribute to the number of new HIV infections. Future research on multiple interacting factors that affect HIV testing behaviors should be considered top priorities. This is of upmost importance because knowing one's HIV status allows those who are infected to seek and receive treatment and prevention services, which are designed to improve health and reduce the likelihood of further transmission.

Keywords: BRFSS; HIV status; HIV testing laws; Self-Reported HIV testing

\section{Introduction}

Forty years ago, the Human Immunodeficiency Virus (HIV) and Acquired Immunodeficiency Syndrome (AIDS) garnered the world's attention. Since then, the HIV/AIDS epidemic remains a major public health concern in the US and globally. While prevention efforts slowed the rates of HIV infection over the first two decades of the epidemic, the CDC estimates suggest that between 2004 and 2007, new HIV infections increased by $15 \%$ [1]. According to the CDC, more than 1.2 million persons aged 13 years and older are living with HIV infection [2]. In 2013, an estimated 47,352 people were diagnosed with HIV infection and another 26,688 persons were diagnosed with AIDS in the US [3]. An estimated 13,712 people with an AIDS diagnosis died in 2012 , and approximately 658,507 people have died due to AIDS since the beginning of the epidemic [3].

It is increasingly recognized that testing plays a critical role in preventing new HIV infections [4]. Although regular HIV testing is 
considered the cornerstone of HIV prevention efforts [5,6], an estimated $18 \%$ of persons infected with HIV in the US are unaware of their HIV status [7] and contribute disproportionately to the number of new infections [8]. CDC estimates that 14 percent of people infected with HIV in the US are unaware of their infection [2] and many of the estimated 50,000 new HIV infections each year are transmitted by people who do not know that they are HIV-positive $[9,10]$. In 2006 , this translated to as many as $50-70 \%$ of new cases of HIV which were spread by people who were unaware of their HIV status [8]. In 2010, CDC indicated that more than half (55\%) of US adults ages 18 to 64 had never been tested for HIV, and in young adults ages 18 to $24,66 \%$ remained untested despite having similar HIV diagnosis rates as other adults [4]. While HIV testing is recommended for persons who are seeking treatment for or have a diagnosis of another STD [11] and HIV testing rates have steadily increased, more than half of Americans still have not been tested for HIV in their lifetime [12]. For example, less than one-half of persons who participated in the National HIV Behavioral Surveillance System Survey conducted among 21 cities in the US reported that they received an STD diagnosis in the 12 months prior to being surveyed [13].

Knowing one's HIV status allows those who are infected to seek and receive treatment and prevention services, which are designed to improve health and reduce the likelihood of further transmission [14]. Research demonstrates that people who know that they have HIV are more likely to reduce their risky sexual behaviors and can lower their viral loads through the consistent use of antiretroviral therapy.

The CDC has identified HIV testing as pivotal to slowing the spread of HIV, recommending that everyone between 13 and 64 get tested for HIV at least once as part of routine health care. At risk individuals are recommended to get tested at least once a year [11]. Routine HIV testing can be used to identify persons infected with HIV who have yet to receive the diagnosis and to link them with primary and secondary prevention services [15]. Previous studies have shown the persistent and unequal distribution of HIV across the US population by age, race, sex, and Socioeconomic Status (SES) [16-18]. A study by the CDC shows consistent differences in HIV testing rates across sex and racial/ethnic groups [19]. The same study indicates also that Black, non-Hispanic persons are more likely to receive HIV testing than White, non-Hispanic or Hispanic persons [19]. Given these disparities in HIV testing and incidence, the current study sought to examine demographic and SES characteristics as they relate to HIV testing among persons aged 18 years and over in the US. We hypothesized that demographic characteristics, SES, region of residence and having engaged in HIV/AIDS risky behaviors would be associated with having received an HIV test.

\section{Methods}

\section{Data source}

We analyzed data from the 2012 BRFSS. The BRFSS is a collaborative project between all of the 50 states in the US, the District of Columbia, three US territories (Puerto Rico, Guam, and the US Virgin Islands) and the CDC. It is designed to measure behavioral risk factors for non-institutionalized adults (aged 18 years of age and older) who reside in the US and its territories. The BRFSS questionnaire is administered on a continuous basis by telephone using random-digit dial sampling methods. The design consists of a probability sample of all households with telephones in the state. A clustering sample design was used to account for differences in the probability of selection and non-response in order to accurately derive US and state-based population estimates. In 2012, more than 450,000 interviews were conducted through the BRFSS. Annual surveys consist of a core set of questions about various health topics; such health-related risk behaviors, chronic health conditions, and use of preventive services. The HIV/AIDS questions used for this study were taken from the core questions. The BRFSS data are publicly available and used for health policy development and advocacy at both the national and state levels.

\section{Measures}

All measures in this study were based on self-reported data obtained from the 2012 BRFSS.

\section{HIV testing}

Self-reported HIV testing was defined by answering "yes" to the question: "Have you ever been tested for HIV?" Having had an HIV test represented the outcome variables with "Yes", "No", "Don't know/ not sure", or "Refused" responses. We included only records with "yes" or "no" responses for "ever been tested" in the analysis. Records with "unknown" or "refused" responses or missing data were excluded from the analysis to minimize underestimation.

\section{Demographic characteristics}

Participants responded to questions about their gender, race or ethnicity, age, education, income, marital status, and region of residence. To examine the role of region of residence on HIV testing, we categorized an individual's region of residency as Black Belt (11 state region of the Southern US), or the remainder of the Southern US, Midwest, Northeast, and West.

\section{HIV/AIDS risky behaviors}

Survey participants responded to the following question to indicate HIV/AIDS risky behaviors:

- You have used intravenous drugs in the past year

- You have been treated for a sexually transmitted or venereal disease in the past year

- You have given or received money or drugs in exchange for sex in the past year

- You had anal sex without a condom in the past year

Responses were "yes", "no", “don't know/not sure”, or refused".

\section{Statistical analysis}

We used univariate analysis to calculate relative frequencies for gender, race or ethnicity, age, education, income, marital status, region of residence, and having engaged in HIV/AIDS risky behaviors to characterize the overall sample. We performed bivariate analysis for an initial assessment of factors independently associated with HIV testing. We included all variables that had achieved $p \leq 0.05$ in the bivariate analysis in our final multivariable logistic regression model, and obtained the Adjusted Odds Ratios (AORs) and 95\% Confidence Intervals (95\% CIs). We performed all statistical analyses with SAS version $9.2[20]$

\section{Results}

Table 1 displays the socio-demographic characteristics of the study population. Of 439,327 participants who responded to the question: "Have you ever been tested for HIV?" 129,846 (30\%) reported having received HIV testing while 309,481 (70\%) reported they did not 
receive HIV testing (Table 1). Of the 129,846 respondents who had been tested for HIV, $59 \%$ were female; $41 \%$ were two or more races and $47 \%$ were between $18-44$ years. The majority (39\%) of the respondent was college graduates; married (50\%); and were from the South region of the US (34\%). Over one third (31\%) of the respondents had annual household incomes less than $\$ 25,000$. In addition, 5\% of the respondents self-reported as having engaged in HIV/AIDS risky behaviors (Table 1).

\begin{tabular}{|c|c|c|c|}
\hline \multirow[t]{3}{*}{ Select Characteristics } & \multicolumn{2}{|c|}{$\begin{array}{l}\text { Self-reported HIV Testing } \\
\qquad(\mathrm{N}=439,327)\end{array}$} & \multirow[t]{2}{*}{$P$ value } \\
\hline & Yes & No & \\
\hline & $\mathrm{n}(\%)$ & n (\%) & \\
\hline Overall & $129,846(29.6)$ & $309,481(70.4)$ & \\
\hline Gender $(n=439,327)$ & & & $<0.0001$ \\
\hline Female & $76,859(59.2)$ & $186,241(60.2)$ & \\
\hline Male & $52,987(40.8)$ & $123,240(39.8)$ & \\
\hline Race/Ethnicity $(n=439,326)$ & & & $<0.0001$ \\
\hline White & $46,797(36.4)$ & $141,499(46.1)$ & \\
\hline Black or African American & $13,094(10.2)$ & $12,455(4.1)$ & \\
\hline Hispanic or Latino & $13,202(10.3)$ & $19,296(6.3)$ & \\
\hline Asian & $745(0.6)$ & $2,047(0.7)$ & \\
\hline $\begin{array}{l}\text { Native Hawaiian or Other Pacific } \\
\text { Islander }\end{array}$ & $135(0.1)$ & $194(0.1)$ & \\
\hline American Indian or Alaska Native & $1,768(1.4)$ & $2,650(0.9)$ & \\
\hline Two or more races & $52,150(40.5)$ & $127,649(41.6)$ & \\
\hline Don't know/not sure & $122(0.1)$ & $390(0.1)$ & \\
\hline Other & $831(0.6)$ & $1,202(0.4)$ & \\
\hline Refused & $1002(0.8)$ & $2,098(0.7)$ & \\
\hline Age Group $(n=435,663)$ & & & $<0.0001$ \\
\hline $18-44$ & $60,905(47.2)$ & $62,815(20.5)$ & \\
\hline $45-64$ & $53,025(41.1)$ & $119,862(39.1)$ & \\
\hline $65-74$ & $11,319(8.8)$ & $66,385(21.6)$ & \\
\hline 75 and above & $3,762(2.9)$ & $57,590(18.8)$ & \\
\hline Level of Education $(n=438,417)$ & & & $<0.0001$ \\
\hline High School or less & $41,559(32.1)$ & $124,818(40.4)$ & \\
\hline Some College & $37,695(29.1)$ & $81,765(26.5)$ & \\
\hline College Graduate & $50,389(38.9)$ & $102,191(33.1)$ & \\
\hline Level of Income $(n=411,487)$ & & & $<0.0001$ \\
\hline Less than $\$ 24,999$ & $38,107(30.6)$ & $78,277(27.3)$ & \\
\hline$\$ 25,000$ to $\$ 49,999$ & $27,328(22.0)$ & $73,221(25.5)$ & \\
\hline$\$ 50,000$ to $\$ 74,999$ & $17,578(14.1)$ & $42,760(14.9)$ & \\
\hline$\$ 75,000$ or more & $34,639(27.8)$ & $70,244(24.5)$ & \\
\hline Do not know/not sure & $6,839(5.5)$ & $22,494(7.8)$ & \\
\hline Marital Status $(n=425,664)$ & & & $<0.0001$ \\
\hline Married & $60,935(49.5)$ & $169,032(55.9)$ & \\
\hline Never Married & $26,862(21.8)$ & $39,446(13.0)$ & \\
\hline Divorced & $23,873(19.4)$ & $37,646(12.4)$ & \\
\hline Separated & $4,568(3.7)$ & $4,838(1.6)$ & \\
\hline Widowed & $6,904(5.6)$ & $51,560(17.0)$ & \\
\hline $\begin{array}{l}\text { Region of Residence } \\
\quad(n=431,311)\end{array}$ & & & $<0.0001$ \\
\hline South Black Belt Statesa & $28,419(22.4)$ & $57,058(18.7)$ & \\
\hline
\end{tabular}

- Page 3 of 6 •

\begin{tabular}{|c|c|c|c|}
\hline Remainderb & $14,044(11.1)$ & $29,019(9.5)$ & \\
\hline Midwest & $25,384(20.0)$ & $80,831(26.5)$ & \\
\hline Northeast & $28,680(22.6)$ & $64,244(21.1)$ & \\
\hline West & $30,190(23.8)$ & $73,442(24.1)$ & \\
\hline HIV Risk ( $n=437,339)$ & & & $<0.0001$ \\
\hline Yes & 6,355 (4.9) & 3,751 (1.2) & \\
\hline No & $122,763(95.1)$ & $304,470(98.8)$ & \\
\hline
\end{tabular}

Table 1: Number* and Percentage of Respondents who reported having had an HIV Test by Select Characteristics: 2012 BRFSS, US.

*Frequencies may vary due to missing values.

aSouth Black Belt States refers to Virginia, North Carolina, South Carolina, Georgia, Florida, Alabama, Mississippi, Tennessee, Louisiana, Arkansas, Texas.

bSouth Remainder refers to Delaware, District of Columbia, Maryland, West Virginia, Kentucky, Oklahoma.

Table 2 shows the bivariate and multivariate associations between self-reported HIV Testing and Select Characteristics. Factors associated with lower odds of HIV testing include being Asian (AOR=0.56; 95\% CI $=0.41,0.78$ ); Native Hawaiian or Other Pacific Islander ( $\mathrm{AOR}=0.42 ; 95 \% \mathrm{CI}=0.18,0.90)$; as well as being from the Midwest $(\mathrm{AOR}=0.78 ; 95 \% \mathrm{CI}=0.73,0.83)$ and the West $(\mathrm{AOR}=0.88$; $95 \% \mathrm{CI}=0.83,0.93$ ) (Table 2). When analyzed by income, having higher annual household income was negatively associated with getting tested for HIV (Table 2). For example, compared to participants with incomes below $\$ 25,000$, those with incomes between $\$ 25,000$ and $\$ 49,999$ had lower odds of getting tested for $\mathrm{HIV}$ ( $\mathrm{AOR}=0.82 ; 95 \% \mathrm{CI}=0.78-0.87$ ), as were those with incomes between $\$ 50,000$ and $\$ 74,999$ ( $\mathrm{AOR}=0.86 ; 95 \% \mathrm{CI}=0.79-0.93)$, and incomes $\geq \$ 75,000$ ( $\mathrm{AOR}=0.87 ; 95 \% \mathrm{CI}=0.81-0.94$ ).

As compared to non-Hispanic Whites, non-Hispanic Blacks or African Americans were more likely to report having had an HIV test $(\mathrm{AOR}=2.03 ; 95 \% \mathrm{CI}=1.86,2.21)$, as were Hispanic or Latino $(\mathrm{AOR}=1.19 ; 95 \% \mathrm{CI}=1.09,1.29)$, two or more races $(\mathrm{AOR}=1.17 ; 95 \%$ $\mathrm{CI}=1.11,1.23)$, and American Indian or Alaska Native $(\mathrm{AOR}=1.58$; $95 \% \mathrm{CI}=1.32,1.88)$. Compared to participants who were in the age group 18-44 years, those in the age group 45-64 years were more likely to report having had an HIV test (AOR $=14.32$; $95 \% \mathrm{CI}=12.51$, $16.44)$, as were those in the age group $65-74$ years $(\mathrm{AOR}=7.23 ; 95 \%$ $\mathrm{CI}=6.36,8.26)$, and those in the age group 75 and above (AOR=2.86; $95 \% \mathrm{CI}=2.49,3.30$ ). We observed a similar pattern in the level of education; those with some college education also had higher odds of getting tested for $\mathrm{HIV}(\mathrm{AOR}=1.65 ; 95 \% \mathrm{CI}=1.56,1.75)$, as those who were college graduates $(\mathrm{AOR}=1.38 ; 95 \% \mathrm{CI}=1.31,1.45)$. As compared to married participants, those who were never married ( $\mathrm{AOR}=1.16$; $95 \% \mathrm{CI}=1.09,1.23$ ) were more likely to get tested for HIV, as were those who were divorced ( $\mathrm{AOR}=1.78 ; 95 \% \mathrm{CI}=1.68,1.89$ ), and separated $(\mathrm{AOR}=1.81 ; 95 \% \mathrm{CI}=1.63,2.00)$ participants (Table 2). In terms of risky behaviors, respondents who reported having engaged in HIV/AIDS risky behaviors were significantly more likely than respondents who did not engage in HIV/AIDS risky behaviors to have received an HIV test $(\mathrm{AOR}=2.45 ; 95 \% \mathrm{CI}=2.19,2.74)$ (Table 2).

\section{Discussion}

Our findings show that seventy percent of the 2012 BRFSS survey participants who responded to the HIV test question have never been tested for HIV. The most plausible explanation for this finding is the concept of who is at risk for HIV. Many people don't get tested because they think they don't have any of the risk factors for HIV infection. 


\begin{tabular}{|c|c|c|c|c|}
\hline \multirow[b]{3}{*}{$\begin{array}{l}\text { Select Character- } \\
\text { istics }\end{array}$} & \multicolumn{4}{|c|}{ Self-reported having tested for HIV } \\
\hline & \multicolumn{2}{|c|}{ Bivariate } & \multicolumn{2}{|c|}{ Multivariate } \\
\hline & $\begin{array}{l}\text { Unadjusted } \\
\text { OR }\end{array}$ & $(95 \% \mathrm{Cl})$ & $\begin{array}{l}\text { Adjusted } \\
\text { OR }\end{array}$ & $(95 \% \mathrm{Cl})$ \\
\hline \multicolumn{5}{|c|}{ Gender } \\
\hline Female (Ref) & 1 & & 1 & \\
\hline Male & 1.04 & $(1.03-1.06)$ & 0.99 & $(0.95-1.04)$ \\
\hline \multicolumn{5}{|c|}{ Age Group } \\
\hline 18-44 (Ref) & 1 & & 1 & \\
\hline $45-64$ & 14.82 & $(14.34-15.37)$ & 14.32 & $(12.51-16.44)$ \\
\hline $65-74$ & 6.77 & (6.54-7.01) & 7.23 & $(6.36-8.26)$ \\
\hline 75 and above & 2.61 & $(2.51-2.71)$ & 2.86 & $(2.49-3.30)$ \\
\hline \multicolumn{5}{|c|}{ Race/Ethnicity } \\
\hline White (Ref) & 1 & & 1 & \\
\hline $\begin{array}{l}\text { Black or African } \\
\text { American }\end{array}$ & 3.18 & $(3.09-3.26)$ & 2.03 & $(1.86-2.21)$ \\
\hline $\begin{array}{c}\text { American Indian or } \\
\text { Alaska Native }\end{array}$ & 2.02 & $(1.90-2.14)$ & 1.58 & $(1.32-1.88)$ \\
\hline Asian & 1.1 & $(1.01-1.20)$ & 0.56 & $(0.41-0.78)$ \\
\hline Hispanic or Latino & 2.07 & $(2.02-2.12)$ & 1.19 & $(1.09-1.29)$ \\
\hline Two or more races & 1.23 & $(1.22-1.25)$ & 1.17 & $(1.11-1.23)$ \\
\hline $\begin{array}{l}\text { Native Hawaiian or } \\
\text { Other Pacific Islander }\end{array}$ & 2.1 & $(1.69-2.62)$ & 0.42 & $(0.18-0.90)$ \\
\hline \multicolumn{5}{|c|}{ Level of Education } \\
\hline$\leq$ High School (Ref) & 1 & & 1 & \\
\hline Some College & 1.48 & $(1.46-1.50)$ & 1.65 & $(1.56-1.75)$ \\
\hline College Grad & 1.38 & $(1.36-1.41)$ & 1.38 & $(1.31-1.45)$ \\
\hline \multicolumn{5}{|c|}{ Level of Income } \\
\hline $\begin{array}{l}\text { Less than } \$ 24,999 \\
\text { (Ref) }\end{array}$ & 1 & & 1 & \\
\hline$\$ 25,000$ to $\$ 49,999$ & 0.77 & $(0.75-0.78)$ & 0.82 & $(0.78-0.87)$ \\
\hline$\$ 50,000$ to $\$ 74,999$ & 0.84 & $(0.83-0.86)$ & 0.86 & $(0.79-0.93)$ \\
\hline$\$ 75,000$ or more & 1.01 & $(0.99-1.03)$ & 0.87 & $(0.81-0.94)$ \\
\hline \multicolumn{5}{|c|}{ Marital Status } \\
\hline Married (Ref) & 1 & & 1 & \\
\hline Divorced & 1.76 & $(1.73-1.79)$ & 1.78 & $(1.68-1.89)$ \\
\hline Never Married & 1.89 & $(1.85-1.92)$ & 1.16 & $(1.09-1.23)$ \\
\hline Separated & 2.62 & $(2.51-2.73)$ & 1.81 & $(1.63-2.00)$ \\
\hline Widowed & 0.37 & $(0.36-0.38)$ & 1.05 & $(0.96-1.14)$ \\
\hline \multicolumn{5}{|c|}{ Region of Residence } \\
\hline Northeast (Ref) & 1 & & 1 & \\
\hline $\begin{array}{l}\text { South Black Belt } \\
\text { Statesa }\end{array}$ & 1.12 & $(1.09-1.14)$ & 1.01 & $(0.94-1.08)$ \\
\hline Remainderb & 1.08 & $(1.06-1.11)$ & 1.06 & $(0.97-1.15)$ \\
\hline Midwest & 0.7 & $(0.69-0.72)$ & 0.78 & $(0.73-0.83)$ \\
\hline West & 0.92 & $(0.90-0.94)$ & 0.88 & $(0.83-0.93)$ \\
\hline \multicolumn{5}{|c|}{ HIV Risk } \\
\hline No (Ref) & 1 & & 1 & \\
\hline Yes & 4.2 & $(4.03-4.38)$ & 2.45 & $(2.19-2.74)$ \\
\hline
\end{tabular}

Table 2: Bivariate and Multivariate associations between self-reported HIV Testing and Select Characteristics: 2012 BRFSS, US.

Note: $\mathrm{OR}=$ Odds Ratio; $\mathrm{Cl}=$ Confidence Interval

aSouth Black Belt States refers to Virginia, North Carolina, South Carolina, Georgia, Florida, Alabama, Mississippi, Tennessee, Louisiana, Arkansas, Texas.

bSouth Remainder refers to Delaware, District of Columbia, Maryland, West Virginia, Kentucky, Oklahoma.
Our finding shows that males were less likely to have received an HIV test than their female counterparts (not statistically significant). This is consistent with the literature [21] and is likely due to sex differences in medical care utilization. Specifically, studies have shown that women are more likely than men to seek medical services due to continuing reproductive care through their childbearing years as well as their lower perceived health status [21,22]. Increased contact with medical providers may provide women with more opportunity to be asked about and offered an HIV test. Considering that men account for $73 \%$ of new HIV infections nationally [23], our finding adds to the supporting data the need for the development of gender specific HIV prevention interventions specifically testing men.

Race/ethnicity differences in HIV testing were also consistent with prior studies [19,24]. Non-Hispanic Blacks or African Americans are more likely to have received an HIV test [19]. The most likely explanation for this finding is related to Black/African-Americans having a greater sense of perceived risk of infection [25] due to the impact of the HIV/AIDS epidemic on African Americans sat every stage of the disease. AIDS remains the leading cause of death among black women between 25-34 years and the second leading cause of death in black men between 35-44 years of age [26,27]. It is known that HIV infection levels are especially high (3.6\%) among blacks aged 40-49, with males in this age group having an HIV prevalence (4.5\%) [27] that approaches the region-wide prevalence in Sub-Saharan Africa (5.0\%) [28]. The rate of AIDS diagnoses for black adults and adolescents was 10 times the rate for whites and nearly 3 times the rate for Hispanics [26]. For Black Men, it was 8 times more than the rate for White Men [26]. African-American women had a 23 times greater diagnosis rate than white women [29]. Thus, knowing someone in the community who has tested positive for HIV or viewing HIV as having a negative impact on one's community may increase the likelihood that a person will be tested. Due to the disproportionately high incidence of HIV in African American communities [24], the effects of HIV may be more personalized to those who identify as part of these communities and thus account for racial differences in HIV testing behaviors. This finding is consistent with past research which suggests that individuals living in predominantly racial or ethnic minority communities and/or HIV prevalent areas may have a greater perceived risk and seek strategies to offset their risks by getting tested [30]. Asians remain less likely than Whites to have received an HIV test [31]. Further research is needed to understand the underlying factors that create and maintain racial/ethnic disparities in HIV testing.

Contrary to our expectation, our results show that participants with a higher level of income were less likely to have been tested for HIV. Two reasons are offered as possible explanations for this finding. A recent study determined that persons living below the poverty line were twice as likely to be HIV-infected as those who lived in the same community but lived above the poverty line ( $2.3 \%$ prevalence vs. $1 \%)$ [32]. Thus, individuals who have low incomes, and who are commonly identified as at-risk, may be aware of their heightened HIV risk of becoming infected (i.e., have greater perceived risk), therefore, may take steps to mitigate that risk (i.e., getting an HIV test) [33]. A second, perhaps interrelated reason may be related to the many HIV testing campaigns that might have been focused on low income communities, which are disproportionately affected by HIV [30].

Our results also demonstrates that respondents from the Southern region of the US were independently more likely to report having received an HIV test. This may be attributable to public health 
campaigns which target the Southern region which has the highest rates of new HIV diagnoses, the largest percentage of people living with the disease, and the greatest mortality rates for HIV/AIDS [34]. CDC data from 2011 indicated that $49 \%$ of HIV diagnoses (includes any new HIV diagnoses regardless of the stage of HIV disease) were located in the Southern US while the Southern region accounts for only $37 \%$ of the US population [35]. The South had the highest HIV diagnosis rate of the four US Census Regions in 2011 (20.9/100,000) [35]. The disproportionate HIV burden in the South is also noted in the President's National AIDS Strategy [36] which states that addressing factors that contribute to the spread of HIV such as poverty, STDs, stigma and treatment inequities is a necessary step in abating the epidemic. Because of the high HIV-related mortality and morbidity rates in the South, which has more people who are considered high risk, there are myriad education and public health campaigns which may lead to increased awareness and testing, consistent with findings from our study [30]. As in previous studies $[37,38]$, results from our study demonstrate that HIV testing was positively associated with having engaged in one or more HIV/AIDS risky behaviors. Our results also show that the odds of having received an HIV test were 2.45 times higher for respondents who reported having engaged in HIV/AIDS risky behaviors, compared with respondents who reported no HIV/AIDS risky behaviors. This could be due to success in adopting HIV-testing in high-risk individuals in this sample and this finding is consistent with what has been reported previously [37].

Our study findings must be interpreted in light of certain limitations regarding the data source. First, the BRFSS is a telephone-based survey and is administered to non-institutionalized adults. Therefore the BRFSS excludes individuals without telephone service, those on military bases, and individuals in institutions. For this reason, generalizability to the entire US population is limited. Secondly, this study relied on self-reported information which may have introduced recall or reporting bias.

\section{Conclusion}

Sociodemographic factors, region of residence, and engaging in HIV/AIDS risky behaviors were associated with HIV testing among 2012 BRFSS survey participants. Our findings suggest that the focus of the HIV/AIDS prevention education and training programs in the US focused on traditionally classified high-risk populations has been effective. Findings from this study undercover an interesting paradox which suggests that populations with higher incomes have been overlooked in efforts to combat HIV/AIDS. Our results suggest that these populations are at greatest risk of not knowing their HIV status and are at risk of unknowingly contributing to the number of new HIV infections. To ensure that persons are aware of their HIV status, additional HIV testing campaigns should target other populations that are least likely to get tested. In addition to persons with higher incomes, these populations include Asians, Native Hawaiians or other Pacific lslanders and persons living in the Midwest. Future research on multiple interacting factors that affects HIV testing behaviors such as the effects of stigma on testing behavior should be considered top priorities. This is of upmost important because knowing one's HIV status allows those who are infected to seek and receive treatment and prevention services, which are designed to improve health and reduce the likelihood of further transmission [14].

\section{References}

1. CDC (2007) HIVIAIDS among Hispanics--United States, 2001-2005. MMWR Morb Mortal Wkly Rep 56: 1052-1057.

2. CDC (2014) Monitoring selected national HIV prevention and care objectives by using HIV surveillance data-United States and 6 dependent areas-2012. HIV Surveillance Supplemental Report 19: 1-61.

3. Folaranmi T, Rubin L, Martin SW, Patel M, MacNeil JR, et al. (2015) Use of Serogroup B Meningococcal Vaccines in Persons Aged $\geq 10$ Years at Increased Risk for Serogroup B Meningococcal Disease: Recommendations of the Advisory Committee on Immunization Practices, 2015. MMWR Morb Mortal Wkly Rep 64: 608-612.

4. CDC (2010) Vital signs: HIV testing and diagnosis among adults--United States, 2001-2009. MMWR Morb Mortal Wkly Rep 59: 1550-1555.

5. Heffelfinger JD OS, Owen SM Hendry RM, Lansky A (2011) HIV Testing: The Cornerstone of HIV Prevention Efforts in the USA. Future Virology 6: 1299-1317.

6. Imrie J, Macdonald N (2009) HIV testing in men who have sex with men: are we ready to take the next HIV testing test? Sex Transm Infect 85: 487-488.

7. CDC (2012) Monitoring Selected National HIV Prevention and Care Objectives by Using HIV Surveillance Data-United States and 6 US Dependent Areas-2010. HIV Surveillance Supplemental Report 17: 1-27.

8. Marks G, Crepaz N, Janssen RS (2006) Estimating sexual transmission of HIV from persons aware and unaware that they are infected with the virus in the USA. AIDS 20: $1447-1450$

9. CDC (2012) Estimated HIV Incidence among adults and adolescents in the United States, 2007-2010. HIV Surveillance Supplemental Report 17: 1-26.

10. Hall HI, Holtgrave DR, Maulsby C (2012) HIV transmission rates from persons living with HIV who are aware and unaware of their infection. AIDS 26 : 893-896.

11. Branson BM, Handsfield HH, Lampe MA, Janssen RS, Taylor AW, et al. (2006) Revised recommendations for HIV testing of adults, adolescents, and pregnant women in health-care settings. MMWR Recomm Rep 55: 1-17.

12. CDC (2013) HIV Testing Trends in the United States, 2000-2011. CDC, Atlanta, Georgia, USA.

13. Sionean C, Le BC, Hageman K, Oster AM, Wejnert C, et al. ((2014) HIV Risk, Prevention, and Testing Behaviors Among Heterosexuals at Increased Risk for HIV Infection-National HIV Behavioral Surveillance System, 21 U.S. Cities, 2010. MMWR Surveill Summaries 63: 1-39.

14. April MD, Walensky RP, Chang Y, Pitt J, Freedberg KA, et al. (2009) HIV testing rates and outcomes in a South African community, 2001-2006: implications for expanded screening policies. J Acquir Immune Defic Syndr 51: 310-316.

15. Steiner RJ, Aquino G, Fenton KA (2013) Enhancing HIVIAIDS, viral hepatitis, sexually transmitted disease, and tuberculosis prevention in the United States through program collaboration and service integration: the case for broader implementation. Sex Transm Dis 40: 663-668.

16. Hall HI, Byers RH, Ling Q, Espinoza L (2007) Racial/ethnic and age disparities in HIV prevalence and disease progression among men who have sex with men in the United States. Am J Public Health 97: 1060-1066.

17. Lane SD, Rubinstein RA, Keefe RH, Webster N, Cibula DA, et al. (2004) Structural violence and racial disparity in HIV transmission. J Health Care Poor Underserved 15: 319-335.

18. Ford K, Lepkowski JM (2004) Characteristics of sexual partners and STD infection among American adolescents. Int J STD AIDS 15: 260-265.

19. CDC (2007) QuickStats: Percentage of adults aged $\geq 18$ years who reported ever being tested for HIV, ${ }^{*}$ by sex and race/ethnicity. National Health Interview Survey, USA.

20. SAS Institute, Cary, NC. 
21. Arrington-Sanders R, Ellen J (2008) Prevalence of self-reported human immunodeficiency virus testing among a population-based sample of urban African-American adolescents. J Adolesc Health 43: 306-308.

22. Bertakis KD, Azari R, Helms LJ, Callahan EJ, Robbins JA (2000) Gender differences in the utilization of health care services. J Fam Pract 49: 147-152.

23. Centers for Disease Control and Prevention (CDC) (2008) Subpopulation estimates from the HIV incidence surveillance system--United States, 2006. MMWR Morb Mortal Wkly Rep 57: 985-989.

24. CDC (2008) Persons tested for HIV--United States, 2006. MMWR Morb Mortal Wkly Rep 57: 845-849.

25. Bond L, Lauby J, Batson H (2005) HIV testing and the role of individual- and structural-level barriers and facilitators. AIDS Care 17: 125-140.

26. CDC (2007) Cases of HIV infection and AIDS in the United States and Dependent Areas, 2005. HIVIAIDS Surveillance 17: 1-54.

27. McQuillan GM, Kruszon-Moran D, Kottiri BJ, Kamimoto LA, Lam L, et al. (2006) Prevalence of HIV in the US household population: the National Health and Nutrition Examination Surveys, 1988 to 2002. J Acquir Immune Defic Syndr 41: 651-656.

28. UNAIDS (2008) Report on the global AIDS epidemic. UNAIDS, Geneva, Switzerland.

29. Hader SL, Smith DK, Moore JS, Holmberg SD (2001) HIV infection in women in the United States: status at the Millennium. JAMA 285: 1186-1192.

30. Taylor SL, Leibowitz A, Simon PA, Grusky O (2006) ZIP code correlates of HIV-testing: a multi-level analysis in Los Angeles. AIDS Behav 10: 579-586.
31. Zaidi IF, Crepaz N, Song R, Wan CK, Lin LS, et al. (2005) Epidemiology of HIVIAIDS among Asians and Pacific Islanders in the United States. MMWR Morb Mortal Wkly Rep 2008 57: 845-849.

32. CDC (2011) Characteristics Associated with HIV Infection Among Heterosexuals in Urban Areas with High AIDS Prevalence --- 24 Cities, United States, 2006--2007. Morbidity and Mortality Weekly Report 60: 1045-1049.

33. DiClemente RJ, Lodico M, Grinstead OA, Harper G, Rickman RL, et al. (1996) African-American adolescents residing in high-risk urban environments do use condoms: correlates and predictors of condom use among adolescents in public housing developments. Pediatrics 98: 269-278.

34. Health \& Science (2014) Southern states are now epicenter of HIVIAIDS in the U.S. The Washing Post, Washington DC, USA

35. CDC (2013) HIV Surveillance Report 2011. National Center for HIVIAIDS, Viral Hepatitis, STD, and TB Prevention 23: 1-84.

36. White House Office of National AIDS Policy (2010) National HIVIAIDS Strategy for the United States. White House Office of National AIDS Policy, Washington DC, USA.

37. Brown JL, Vanable PA (2007) Alcohol use, partner type, and risky sexual behavior among college students: Findings from an event-level study. Addict Behav 32: 2940-2952.

38. Wechsler H, Dowdall GW, Davenport A, Castillo S (1995) Correlates of college student binge drinking. Am J Public Health 85: 921-926. 